\title{
JULIAN GEORGIEVICH MOLOTKOVSKY To the 75th anniversary
}

DOI: $10.1134 / \mathrm{S} 1990747810030116$

On April 7,2010, Professor Julian Molotkovsky, the foremost authority in the area of lipid chemistry and membranology, has turned 75. His scientific work is well known both inside Russia and abroad. Research activity of Julian Molotkovsky is inherently connected to the Shemyakin and Ovchinnikov Institute of Bioorganic Chemistry, Russian Academy of Sciences. He is one of the gifted research enthusiasts who laid the foundation of the Institute, created by the academician Mikhail Shemyakin in 1959, and whom the Institute owes its leadership in the field of physico-chemical biology. Upon completion and defense of his candidate dissertation, Julian joined the team of the Laboratory of Lipid Chemistry headed by Professor Lev Bergelson. Lipidology, which at the time point was being established as a branch of bioorganic chemistry, became the subject of committed and fruitful work of Julian Molotkovsky for many years. His main research interests included synthesis of scarcely available phospholipids and development of methods to separate racemic alcohol mixtures, along with original approaches to synthesis of unsaturated lipids. Starting from the mid-1970s, research of Julian Molotkovsky focused on design of fluorescent and photoaffinity lipids as efficient instruments to study physicochemical properties of artificial and biological membranes. Using the lipid probes, Julian performed a number of important studies of phospholipid bilayer membranes. New regularities in structure of blood lipoproteins, erythrocyte membranes, and influenza virus envelopes were discovered. The results of the studies provided ground for his doctoral dissertation defended in 1985. He was awarded State prize the same year.
Starting from the beginning of 1990s, Julian Molotkovsky headed the Laboratory of Lipid Chemistry (Institute of Bioorganic Chemistry, RAS) for over 15 years. Under his direction, fruitful collaboration in the area of application of fluorescent lipid probes in membrane studies was established with many scientific groups in our country and with researchers from the USA, Sweden, and Ukraine. In the mid-1990s Prof. Molotkovsky initiated a research aimed at a design of novel liposome systems for targeted delivery of anti-tumor drugs. Today, this branch of studies belongs to the rapidly developing field of nanobiotechnology.

Currently, Professor and Chief Researcher of the Institute of Bioorganic Chemistry, Julian Molotkovsky continues his tireless and fruitful research in the Laboratory of Lipid Chemistry passing on his priceless professional experience to younger colleagues. He belongs to the Atlas team supporting the dome of true Science. He authored about 200 publications; some of them were published in Biologicheskie membrany and undoubtedly increased the journal rating.

The Editorial Board of the Journal is grateful to Julian for many years of collaboration and invaluable contribution to our activity. Together with friends and colleagues, we congratulate cordially Julian Molotkovsky with the jubilee and wish him many years of work, health, and happiness.

E.L. Vodovozova
E.V. Dyatlovitskaya
V.V. Bezuglov
S.S. Kolesnikov

